\title{
O IMPACTO DO PROGRAMA DE MICROCRÉDITO RURAL (AGROAMIGO) NA MELHORIA DAS CONDIÇÕES DE VIDA DAS FAMÍLIAS BENEFICIADAS NO ESTADO DO CEARÁ: UM ESTUDO DE CASO ${ }^{1}$
}

Harine Matos Maciel $^{2}$

Ahmad Saeed Khan ${ }^{3}$

Resumo: O presente estudo objetivou verificar o impacto do Programa de Microcrédito Rural (Agroamigo) na melhoria das condições das famílias beneficiadas no estado do Ceará. Os dados analisados foram obtidos a partir de uma pesquisa de campo no município de Quixadá. Como técnicas de análise, foram adotados a análise tabular, descritiva e gráfica, e os testes t-Student, Tukey e Kruskall-Wallis, para comparação das médias e proporções, respectivamente. $\mathrm{O}$ emprego agropecuário, por hectare, é maior nas atividades de bovinocultura e suinocultura. A renda da maioria dos beneficiários vem da agricultura e a dos não beneficiários, de pensões e aposentadorias. A maior média da renda agropecuária por hectare foi obtida da atividade de suinocultura, pois esta tem um retorno financeiro mais rápido que as atividades de bovinocultura e ovinocultura. $\mathrm{O}$ Índice de Qualidade de Vida dos beneficiários e não beneficiários é de média qualidade de vida. As maiores contribuições do Índice de Qualidade de Vida originaram-se das condições de moradia, educação e saúde, e a menor, do lazer. O Programa Agroamigo tem agilizado o acesso ao crédito para os agricultores familiares.

Palavras-chaves: microcrédito rural, emprego, renda, qualidade de vida, Ceará.

Recebido em 12/02/09; Aceito em 05/05/2009.

Economista. Mestre em Economia Rural pela UFC. E-mail: harinematos@yahoo.com.br.

3 Engenheiro Agrônomo. Ph.D. em Economia Agrícola e Recursos Naturais. Professor Titular do Departamento de Economia da UFV. E-mail: saeed@ufc.br. 


\section{Introdução}

O crédito ágil, oportuno e compatível com as necessidades de seus tomadores, é um importante instrumento para o desenvolvimento econômico e social, pois gera oportunidades de crescimento, ocupação e renda. Conforme Neri e Medrado (2005), a grande vantagem do microcrédito, em seu aspecto de política social, é que ele gera incentivos para que seu cliente se envolva em atividades produtivas e possa pagar sua dívida, o que faz com que ele tenha capacidade de aumentar a sua renda.

A experiência pioneira de microcrédito, no Brasil, foi a União Nordestina de Assistência a Pequenas Organizações (UNO), criada em 1973, com o objetivo de apoiar os micro e pequenos empreendimentos da região Nordeste, por meio de financiamento e capacitação gerencial.

Dado o sucesso de outros programas no Brasil, o Banco do Nordeste do Brasil (BNB) teve uma iniciativa pioneira, ao lançar o programa Crediamigo em 1997, que passou a atuar, diretamente, na concessão de microcrédito. Apesar de ser uma iniciativa pioneira, o Crediamigo só abrange o setor urbano, faltando atender a grande parcela da população que reside na área rural. Dessa forma, em 2005, o BNB criou o Programa de Microcrédito Rural - Agroamigo, que tem como base o Programa Crediamigo, mas com as devidas adaptações para o setor rural. O Programa está presente em, aproximadamente, 170 agências do BNB e atende a 517 municípios do Nordeste brasileiro, norte de Minas Gerais e do Espírito Santo.

O Agroamigo tem o objetivo principal de expandir o atendimento aos agricultores familiares de pequeno porte, mediante a concessão de microcrédito produtivo e orientado, contemplando maior agilidade no processo de concessão do crédito.

Diante do exposto, é necessário verificar o impacto do programa agroamigo na melhoria das condições de vida dos beneficiários do programa. 
Os objetivos do trabalho são analisar a geração de emprego e renda nas propriedades rurais dos produtores beneficiários pelo Programa de Microcrédito Rural (Agroamigo) e verificar a qualidade de vida das famílias beneficiadas por este.

\section{Microcrédito: Aspectos conceituais e suas características}

O termo microcrédito tem diferentes definições. Para Gulli (1998), apud Neri e Medrado (2005), ele consiste em serviços financeiros, de pequena escala, que envolvam valores baixos, enquanto Schreiner (2001), apud Neri e Medrado (2005), não definiu o termo pelo valor emprestado, mas sim como o crédito concedido a pessoas de baixa renda.

As principais características dos programas bem sucedidos de microcrédito, segundo Rhyne e Holt (1994), são a criação de grupos de pessoas que tomam emprestado juntas e responsabilizam-se, conjuntamente, pelo pagamento das dívidas; o contato direto dos agentes do banco com a realidade e ambiente dos clientes; os empréstimos de baixos valores e progressivos, de acordo com a inadimplência do cliente; a flexibilidade das formas e datas dos pagamentos diante de choques exógenos; os juros não subsidiados; e o não subsídio aos empréstimos ou a mentalidade de perdoá-los.

\section{O Programa de Microcrédito Rural - AGROAMIGO}

O Agroamigo iniciou-se em 2005, e sua fonte de recursos provém do Fundo Constitucional de Financiamento do Nordeste (FNE). A implantação do projeto-piloto ocorreu nas agências de Floriano (P1) e Oeiras (P1). O Programa está presente em, aproximadamente, 170 agências do BNB e atende a 517 municípios do Nordeste brasileiro, norte de Minas Gerais e do Espírito Santo, com a colocação de 350 assessores de Microcrédito Rural. 
O Agroamigo tem o objetivo geral de expandir o atendimento aos agricultores familiares de pequeno porte, inicialmente beneficiários do Programa Nacional de Fortalecimento da Agricultura Familiar (PRONAF) - Grupo B, mediante a concessão de microcrédito produtivo e orientado.

No Programa Agroamigo há uma figura essencial, que é o assessor de crédito. Este é um profissional de nível médio, com qualificação na área de extensão rural, e deverá apresentar habilidade para promover e facilitar processos, devendo, preferencialmente, pertencer à comunidade local, com vivência na zona rural, visando garantir facilidade de diálogo e compreensão dos processos produtivos, permitindo maior fluidez nos trabalhos de campo.

\section{Indicadores de qualidade de vida}

Muitos autores, como Da Veiga (2006), afirmaram que o aumento do Produto Interno Bruto (PIB) não implica melhoria na qualidade de vida, pois este não revela como a riqueza do país está sendo distribuída. Dessa forma, o PIB não pode ser utilizado, como variável fundamental, na busca do desenvolvimento social, assunto que se tornou uma preocupação mundial crescente nos últimos anos, surgindo, assim, o conceito de qualidade de vida.

De acordo com Viana (1980), os países em desenvolvimento tem se preocupado mais com o desenvolvimento econômico do que com o social, quando ambos deveriam ser simultâneos. Isso faz com que o social seja relegado a segundo plano, nas políticas públicas em geral.

Segundo Guerrero e Hoyos (1983), a elaboração do índice de qualidade de vida está condicionada ao tipo de população estudada, pois as necessidades de famílias pobres são diferentes das de famílias ricas. Os componentes básicos, como alimentação, saúde e habitação, são mais importantes na categoria pobre do que na rica. 
No trabalho de Monte (1999) usou-se um Índice de Qualidade de Vida (IQV), que contemplou indicadores como aspectos econômicos, condições de moradia, nível de consumo, educação, lazer e informação, para medir ganhos ou perdas na qualidade de vida da população, antes e depois da implantação do Porto de Pecém.

Já no trabalho de Lima, Mendonça, Silva e Vidal (2007), obteve-se o índice de qualidade de vida nos municípios do estado do Acre, levando em consideração os indicadores que contemplam saúde, educação, renda, violência e saneamento básico.

Cardoso, Ribeiro e Rocha (2007) utilizaram os indicadores de saúde, renda, educação, habitação e acesso a bens e serviços, segurança pública e vulnerabilidade para avaliar o índice de qualidade de vida nas microrregiões mineiras. Concluiu-se que o nível de vida da população depende do nível de renda "per capita" e das condições dos domicílios e do acesso a bens e serviços.

Observa-se que não há uma definição exata do que seja qualidade de vida, mas há várias tentativas de definição. Neste trabalho, será feita a mensuração da qualidade de vida dos beneficiários e não-beneficiários do Programa de Microcrédito Rural (Agroamigo), utilizando-se os seguintes indicadores: condições de saúde, acesso à educação, aspectos habitacionais, condições sanitárias e de higiene, situação econômica e condições de lazer.

\section{Metodologia}

\section{1. Área geográfica de estudo e fonte dos dados}

Este estudo compreende o município de Quixadá, pois este foi um dos primeiros municípios do estado do Ceará a receber o Programa de Microcrédito Rural (Agroamigo), no primeiro semestre de 2005. 
Os dados foram coletados de entrevistas junto aos beneficiários e nãobeneficiários do Programa Agroamigo, no município de Quixadá no Estado do Ceará. Foram entrevistados 15 não-beneficiários e 45 beneficiários, divididos igualmente entre as atividades de bovinocultura (15), ovinocultura (15) e suinocultura (15), que foram beneficiados no início do programa e selecionados, aleatoriamente, em cada atividade. É importante ressaltar que $75 \%$ dos projetos financiados estão nessas atividades, de acordo com o Programa Agroamigo, o que justifica a escolha destas.

\subsection{Método de análise}

\subsubsection{Análise do Programa sobre o emprego}

O total do emprego agrícola e pecuário na propriedade do beneficiário do Agroamigo foi determinado pelo trabalho requerido na área cultivada na propriedade, conforme descrito a seguir:

$\mathrm{E}_{a j}=\sum_{c=1}^{d} t_{c b j} a_{c b j}+\sum_{v=1}^{s} t_{v b j} a_{v b j}$,

em que $\mathrm{E}_{a j}$ é emprego agrícola e pecuário total na propriedade; $\mathrm{t}_{c b j}$, quantidade da mão-de-obra empregada, por hectare, na cultura c, na propriedade do beneficiário j, do Agroamigo; $\mathrm{a}_{c b j}$, área cultivada com cultura c, na propriedade do beneficiário j, do Agroamigo; $\mathrm{t}_{v b j}$, quantidade da mão-de-obra empregada na atividade pecuária v pelo beneficiário j; a vbj , atividades pecuárias na propriedade do beneficiárioj, do Agroamigo; $\mathrm{c}=1, \ldots, \mathrm{d}$ culturas; $\mathrm{v}, 1, \ldots, \mathrm{s}$ atividades de origem pecuária.

No cálculo das mudanças no trabalho agropecuário total utilizou-se a 
diferença da mão-de-obra total empregada na propriedade dos beneficiários e não-beneficiários do Programa Agroamigo:

$\Delta \mathrm{E}_{a}=\left(\sum_{j=1}^{m} \sum_{c=1}^{d} t_{c b j} a_{c b j}+\sum_{j=1}^{m} \sum_{v=1}^{s} t_{v b j} a_{v b j}\right)-\left(\sum_{p=1}^{v} \sum_{c=1}^{d} t_{c n p} a_{c n p}+\sum_{p=1}^{v} \sum_{v=1}^{s} t_{v n p} a_{v n p}\right)$,

em que $\Delta \mathrm{E}_{a j}$ é mudança no emprego agrícola e pecuário total resultante do Agroamigo; $\mathrm{t}_{c b j}, \mathrm{t}_{v b j}, \mathrm{a}_{c b j}$ e $\mathrm{a}_{v b j}$, valores descritos anteriormente; $\mathrm{t}_{c n p}$, quantidade de mão-de-obra empregada por hectare na cultura $c$, na propriedade dos não-beneficiários p do Agroamigo; $a_{c n p}$, área cultivada com cultura c, na propriedade dos não-beneficiários $\mathrm{p} ; \mathrm{t}{ }^{\mathrm{n} n}$, quantidade da mão-de-obra empregada na atividade pecuária v pelo não-beneficiário $\mathrm{p} ; \mathrm{a}_{v n p}$, atividades pecuárias na propriedade do não-beneficiário $\mathrm{p} ; \mathrm{j}=$ $1, \ldots, \mathrm{m}$, beneficiários do programa; $\mathrm{p}=1, \ldots, \mathrm{y}$, não-beneficiários do programa; $\mathrm{c}=1, \ldots, \mathrm{d}$, culturas.

\subsubsection{Análise do Programa sobre a renda}

A variação na renda total das atividades agrícolas e pecuárias do beneficiário do Agroamigo, em relação ao não-beneficiário, será:

$\Delta \mathrm{R}_{a p j}=\left(\sum_{c=1}^{d} P_{c b j} A_{c b j} Z_{c b j}-\sum_{c=1}^{d} P_{c n p} A_{c n p} Z_{c n p}\right)+\left(\sum_{v=1}^{s} P_{v b j} q_{v b j}-\sum_{v=1}^{s} P_{v n p} q_{v n p}\right)$,

em que $\mathrm{P}_{c b j}$ é preço da cultura c recebido pelo produtor beneficiário j do Agroamigo; 
$\mathrm{P}_{c n p}$, preço da cultura $\mathrm{c}$ recebido pelo produtor não-beneficiário $\mathrm{p}$ do Agroamigo;

A cbj ,área colhida da cultura c pelo produtor beneficiário j do Agroamigo;

$\mathrm{A}^{c n p}$, área colhida da cultura c pelo produtor não-beneficiário $\mathrm{p}$ do Agroamigo;

$\mathrm{Z}_{c b j}$, produtividade da cultura c obtida pelo produtor beneficiário $\mathrm{j}$ do Agroamigo;

$\mathrm{Z}_{\text {cnp }}$, produtividade da cultura c obtida pelo produtor não-beneficiário $\mathrm{p}$ do Agroamigo;

$\mathrm{P}_{v b j}$, preço do produto $\mathrm{v}$, de origem pecuária, recebido pelo beneficiário $\mathrm{j}$;

$\mathrm{q}_{v b j}$, quantidade produzida do produto $\mathrm{v}$, de origem pecuária, pelo beneficiário j do Agroamigo;

$\mathrm{P}_{v n p}$, preço do produto $\mathrm{v}$, de origem pecuária, recebido pelo nãobeneficiário p do Agroamigo;

$\mathrm{q}_{v n p}$, quantidade produzida do produto v, de origem pecuária, pelo nãobeneficiário p do Agroamigo.

$\mathrm{c}=1, \ldots, \mathrm{d}$ culturas; $\mathrm{v}=1, \ldots, \mathrm{s}$ atividades de origem pecuária; $\mathrm{j}=1, \ldots, \mathrm{m}$ beneficiários do programa; $\mathrm{p}=1, \ldots, \mathrm{y}$ não-beneficiários do programa; $\Delta R_{a p j}=$ variação da renda total das atividades agrícolas e pecuárias. 


\subsection{Mensuração do Índice de Qualidade de Vida}

No cálculo do IQV foram considerados os seguintes indicadores: condição de domicílio, acesso a serviços de saúde, acesso a serviço de educação, aspectos habitacionais, condições sanitárias e de higiene, situação econômica e condições de lazer das famílias entrevistadas no município de Quixadá.

I) Condições de saúde

Para este indicador, foi considerada a disponibilidade de serviços de saúde às famílias dos entrevistados, tais como:

a) Ausência de atendimento médico e ambulatorial (0); b) Atendimento de primeiros socorros (1); c) Atendimento por agente de saúde (2); d) Atendimento médico (4).

II) Acesso à educação

Foi considerada a existência ou ausência de serviços educacionais para as famílias dos entrevistados:

a) Ausência de escolas públicas e comunitárias (0); b) Escolas de curso de alfabetização (1); c) Escolas de ensino fundamental (2); d) Escolas de ensino médio (3).

III) Aspectos habitacionais

Foram considerados os seguintes aspectos habitacionais do entrevistado: condições de domicílio, tipo de construção da sua residência e energia utilizada na residência. 
i) Condições de domicílio - a) Casa cedida (0); b) Casa alugada (1); c) Casa própria(2).

ii) Tipo de construção da residência - a) Casa de taipa (0); b) Casa de tijolo, sem reboco e piso (1); c) Casa de tijolo, com reboco e piso (2);

d) Casa de tijolo, com reboco e piso de cerâmica (3).

iii) A iluminação usada na residência - a) Lamparina ou vela(0); b) Lampião a querosene ou gás(1); c) Energia elétrica(2).

IV) Condições sanitárias e de higiene

Este indicador foi formatado com base em quatro variáveis:

i) Destino dado aos dejetos humanos - a) Jogado a céu aberto (0); b) Dirigido à fossa (1); c) Rede de esgoto (2).

ii) Origem da água para o consumo humano - a) Caminhões pipa (1); b) Diretamente do açude ou rio (2); c) Poço ou cacimba (3); d) Chafariz (4); e) Água encanada da rede pública (5).

iii) Tipo de tratamento dado à água para consumo humano - a) Nenhum tratamento (0); b) Com tratamento(1).

iv) Destino dado ao lixo domiciliar - a) Jogado ao solo ou queimado(0); b) Enterrado(1); c) Coleta domiciliar(2).

V) Indicador econômico

A renda mensal dos trabalhadores é essencial para a manutenção de um padrão mínimo de conforto às famílias. Foi utilizada a renda mensal da família entrevistada (renda agropecuária + renda não-agropecuária) como indicador econômico. Utilizou-se o salário mínimo de $\mathrm{R} \$ 415,00$.

As famílias foram divididas em quatro grupos, a seguir:

a) $\mathrm{R} \leq 415,00$ (1); b) $415,00<\mathrm{R} \leq 830,00$ (2); c) $830,00<\mathrm{R} \leq 1.245,00$ (3); d) R > 1.245,00 (4). 
VI) Indicador lazer

Este indicador foi calculado com base no tipo de entretenimento disponível para ele e sua família, considerando-se os seguintes escores:

a) Nenhuma infra-estrutura de lazer (0); b) Existência de salões de festas ou campos de futebol ou festas religiosas ou populares (1); c) Existência de campos de futebol e salões de festas e, ou, festas religiosas ou populares (2); d) Existência de campos de futebol e salões de festas e festas religiosas ou populares (3).

Com base no Índice de Desenvolvimento Humano (IDH), calculado pelo Programa das Nações Unidas para o Desenvolvimento (PNUD), o Índice de Qualidade de Vida (IQV) varia de 0 a 1 . Quanto mais próximo de 1 , melhor o nível de qualidade de vida da família do entrevistado. Dentro desses limites, optou-se por estabelecer os seguintes critérios:

a) Baixo nível do IQV: $0 \leq \mathrm{IQV}<0,5$; b) Médio nível do IQV: 0,5 $\leq \mathrm{IQV}$ $<0,8$; c) Alto nível do IQV: $0,8 \leq$ IQV d" 1 .

O IQV é definido, matematicamente, por

$\mathrm{IQV}=\frac{1}{F} \sum_{L=1}^{F} C_{L}$

em que $\mathrm{L}=1,2,3 \ldots, \mathrm{F}$ são indicadores de qualidade de vida.

A contribuição de cada indicador para o Índice de Qualidade de Vida foi obtida da seguinte maneira:

$\mathrm{C}_{L}=\frac{1}{M} \sum_{j=1}^{m}\left(\frac{1}{n} \sum_{i=1}^{n} \frac{E_{i l j}}{E_{\max i l j}}\right)$,

em que IQV é Índice de Qualidade de Vida da população beneficiada por determinada atividade; Eilj, escore do i-ésimo variável do indicador 1, obtido pelo j-ésimo beneficiário; $\mathrm{j}=1,2,3 \ldots, \mathrm{m}$, beneficiários do 
programa; $i=1,2,3 \ldots, n$, variáveis do indicador $1 ; E_{\text {max } i l j}$, escore máximo do i-ésimo variável do indicador $1 ; C_{L}$, contribuição do indicador $\mathrm{L}$ ao Índice de Qualidade de Vida dos beneficiários.

\subsection{Testes Utilizados}

Foram utilizados os testes estatísticos de Tukey na comparação múltipla das médias das rendas; t-Student, para dados pareados e não-pareados, na comparação das médias; e o teste Teste H, de Kruskall-Wallis, na comparação das proporções dos beneficiários e não-beneficiários em relação com algumas variáveis.

\section{Resultados e discussão}

\subsection{Análise do Índice de Qualidade de Vida dos beneficiários e não-beneficiários pelo Agroamigo}

Classificou-se a qualidade de vida, em categorias, como baixo nível, médio nível e alto nível de qualidade de vida. A Tabela 1 apresenta a participação de cada indicador na composição do IQV dos beneficiários por atividade e dos não-beneficiários. Nesse propósito, verifica-se que os indicadores de moradia e saúde destacam-se como os de maior contribuição, o que indica a relevância dos indicadores no bem-estar dos entrevistados. $\mathrm{O}$ indicador lazer apresentou o pior resultado.

Como se observa na Tabela 1, o IQV apresentou valor de 0,56 para os não-beneficiários de 0,53 a 0,61 para os beneficiários, de acordo com a atividade, ambos dentro do intervalo de média qualidade de vida, mas bem próximo do limite da baixa qualidade de vida, excluindo a atividade de suinocultura. 
Tabela 1 - Participação dos indicadores na composição do IQV no município de Quixadá - CE - 2008

\begin{tabular}{|c|c|c|c|c|c|c|c|c|}
\hline \multirow{3}{*}{ Indicador } & \multicolumn{6}{|c|}{ Beneficiários } & \multirow{2}{*}{\multicolumn{2}{|c|}{ Não-Beneficiários }} \\
\hline & \multicolumn{2}{|c|}{ Bovinocultura } & \multicolumn{2}{|c|}{ Ovinocultura } & \multicolumn{2}{|c|}{ Suinocultura } & & \\
\hline & $\begin{array}{c}\text { Freq. } \\
\text { Absoluta }\end{array}$ & $\begin{array}{c}\text { Freq. } \\
\text { Relativa }(\%)\end{array}$ & $\begin{array}{c}\text { Freq. } \\
\text { Absoluta }\end{array}$ & $\begin{array}{c}\text { Freq. } \\
\text { Relativa }(\%)\end{array}$ & $\begin{array}{c}\text { Freq. } \\
\text { Absoluta }\end{array}$ & $\begin{array}{c}\text { Freq. } \\
\text { Relativa(\%) }\end{array}$ & $\begin{array}{c}\text { Freq. } \\
\text { Absoluta }\end{array}$ & $\begin{array}{c}\text { Freq. } \\
\text { Relativa(\%) }\end{array}$ \\
\hline Saúde & 0,12 & 21,64 & 0,12 & 22,91 & 0,12 & 20,08 & 0,12 & 21,43 \\
\hline Educa & 0,11 & 19,18 & 0,09 & 16,14 & 0,10 & 16,43 & 0,09 & 16,07 \\
\hline Morad & 0,14 & 24,42 & 0,14 & 26,67 & 0,15 & 24,75 & 0,14 & 25,00 \\
\hline $\begin{array}{l}\text { Cond. } \\
\text { Sanitá }\end{array}$ & 0,07 & 12,15 & 0,07 & 13,97 & 0,08 & 12,72 & 0,07 & 12,50 \\
\hline Lazer & 0,04 & 7,87 & 0,03 & 5,21 & 0,05 & 7,76 & 0,05 & 8,93 \\
\hline Econ & 0,08 & 14,75 & 0,08 & 15,10 & 0,11 & 18,26 & 0,09 & 16,07 \\
\hline IQV & 0,56 & 100,00 & $\mathbf{0 , 5 3}$ & 100,00 & 0,61 & 100,00 & 0,56 & 100,00 \\
\hline
\end{tabular}

Fonte: Resultados da pesquisa.

$\mathrm{Na}$ atividade de bovinocultura, a maior contribuição do IQV originou-se das condições de moradia $(24,42 \%)$, saúde $(21,64 \%)$ e educação $(19,18 \%)$; na ovinocultura, de moradia $(26,67 \%)$, saúde $(22,91 \%)$ e educação (16,14\%); e na suinocultura, da moradia $(24,75 \%)$, saúde $(20,08 \%)$ e educação $(16,43 \%)$, o que confirma a similaridade entre as atividades, segundo a contribuição dos indicadores na composição do índice de qualidade de vida.

Os indicadores que menos contribuíram para o IQV foram as condições sanitárias e o lazer. Na atividade de bovinocultura, as condições sanitárias contribuíram com $12,15 \%$ e o lazer com $7,87 \%$; na ovinocultura, as condições sanitárias foram de $13,97 \%$ e o lazer, 5,21\%; na suinocultura, as condições sanitárias contribuíram com $12,72 \%$ e o lazer, 7,76\%. Para os não-beneficiários, os indicadores que menos contribuíram para o IQV foram também o lazer $(8,93 \%)$ e as condições sanitárias $(12,50 \%)$, o que indica uma similaridade entre as duas amostras.

A Tabela 2 mostra a distribuição relativa dos entrevistados, segundo o nível de qualidade de vida. Quando se analisam os beneficiários por atividades, constata-se que, em bovinocultura e suinocultura, $20 \%$ possuía baixo nível de qualidade de vida, enquanto na ovinocultura, 13\%. Já o médio nível de qualidade de vida, na bovinocultura e suinocultura, foi de $80 \%$, enquanto na ovinocultura foi de $87 \%$. Observou-se que os beneficiários da atividade de ovinocultura tiveram a melhor qualidade de vida em relação aos beneficiários das outras atividades. $\mathrm{O}$ melhor 
desempenho do indicador condições de moradia dessa atividade pode ser considerado o principal fato para esse resultado. Constatou-se que nenhum beneficiário possuía alto nível de qualidade de vida, enquanto 66,66 dos não-beneficiários tinham médio nível; 26,66\%, baixo nível; e $6,68 \%$, alto nível de qualidade de vida.

É importante citar que, quando se analisa o índice de qualidade de vida, os seus indicadores são diretamente relacionados com políticas públicas destinadas a saneamentos, escolas, condições de higiene e de lazer, e não há um efeito direto do Programa Agroamigo sobre esses indicadores.

Tabela 2 - Distribuição relativa dos beneficiários e não-beneficiários, segundo o nível de qualidade de vida no município de Quixadá - CE - 2008

\begin{tabular}{l|c|c|c|c}
\hline \multirow{2}{*}{$\begin{array}{c}\text { Nível de } \\
\text { Qualidade de Vida }\end{array}$} & \multicolumn{3}{|c|}{ Beneficiários } & \multirow{2}{*}{ Não-Beneficiários } \\
\cline { 2 - 4 } & Bovinocultura & Ovinocultura & Suinocultura & \\
\cline { 2 - 4 } & $\begin{array}{c}\text { Freq. Relativa } \\
(\%)\end{array}$ & $\begin{array}{c}\text { Freq. Relativa } \\
(\%)\end{array}$ & $\begin{array}{c}\text { Freq. } \\
\text { elativa } \\
(\%)\end{array}$ & $\begin{array}{c}\text { Freq. Relativa } \\
(\%)\end{array}$ \\
\hline Baixo Nível & 20,00 & 13,00 & 20,00 & 26,66 \\
Médio Nível & 80,00 & 87,00 & 80,00 & 66,66 \\
Alto Nível & 0,00 & 0,00 & 0,00 & 6,68 \\
Total & $\mathbf{1 0 0 , 0 0}$ & $\mathbf{1 0 0 , 0 0}$ & $\mathbf{1 0 0 , 0 0}$ & $\mathbf{1 0 0 , 0 0}$ \\
\hline
\end{tabular}

Fonte: Resultados da pesquisa.

Utilizou-se o teste $\mathrm{t}$ - Student, na Tabela 3, para dados não pareados, com o objetivo de testar se as médias dos IQV eram, ou não, significativamente diferentes nas atividades estudadas. 
Tabela 3 - Teste t para comparação do Índice de Qualidade de Vida Médio entre as atividades de bovinocultura, ovinocultura, suinocultura e as atividades agropecuárias dos nãobeneficiários no município de Quixadá - CE - 2008

\begin{tabular}{ccccc}
\hline IQV Médio & Atividades & Teste $t$ & Prob. Sig. \\
& & & \\
\hline Bovinocultura & Não-Beneficiário & $-0,790$ & 0,938 \\
Ovinocultura & Não-Beneficiário & $-0,647$ & 0,523 \\
Suinocultura & Não-Beneficiário & 0,619 & 0,503 \\
\hline
\end{tabular}

Fonte: Resultados da pesquisa.

Conclui-se que as médias dos IQVs não eram significativamente diferentes, quando se comparava beneficiário (bovinocultura, ovinocultura e suinocultura) com não-beneficiário, dado o nível de 5\% (cinco por cento) de significância.

\subsection{Efeito do Programa Agroamigo sobre o emprego}

A Tabela 4 mostra que o emprego agropecuário, por hectare, era maior nas atividades de bovinocultura e suinocultura, pois nestas estavam as maiores áreas plantadas, razão por que necessitavam de maior número de mão-de-obra. Na atividade de ovinocultura dos não-beneficiários, as áreas plantadas eram menores, o que levava à menor demanda de mãode-obra.

Para comparar o emprego agropecuário por hectare entre as atividades dos beneficiários e não-beneficiários, aplicou-se o teste não-paramétrico de Kruskal-Wallis, pois não se verificaram as condições necessárias para aplicação de um teste paramétrico que admitisse a distribuição normal da variável e a variância constante para testar se havia igualdade das médias do emprego agropecuário, por hectare, nas atividades no município de Quixadá, no estado do Ceará, no ano de 2008. 
O teste aponta que, dado um nível de significância de 5\% (cinco por cento), não havia igualdade na utilização da mão-de-obra, por hectare, entre as atividades de bovinocultura, ovinocultura, suinocultura e a atividade dos não-beneficiários.

Tabela 4 - Emprego agropecuário, por hectare, dos beneficiários e nãobeneficiários, segundo atividades pecuárias no município de Quixadá - CE - 2008

\begin{tabular}{c|c|c|c|c|c}
\hline \multicolumn{3}{|c|}{ Beneficiários } & Não- & Teste & Prob. \\
Bovinocultura & Ovinocultura & Suinocultura & Beneficiários & H-KW & Sig. \\
\hline 0,23 & 0,10 & 0,22 & 0,10 & 8,779 & 0,032 \\
\hline
\end{tabular}

Fonte: Resultados da pesquisa.

\subsection{Efeito do Programa Agroamigo sobre a renda}

A Tabela 5 mostra que, dos beneficiários entrevistados, 37,8\% recebiam até 1 salário mínimo; $31,2 \%$, de 1 a 2 salários mínimos; e 17,8\%, de 3 a 4 salários mínimos. Dos não-beneficiários, 46,7\% tinham renda de 2 a 3 salários mínimos; 26,7\%, de 1 a 2 salários mínimos; e 26,7\%, até 1 salário mínimo.

De acordo com a estatística H, de Kruskall-Wallis, para comparação entre as proporções das faixas salariais, percebe-se que existem diferenças significativas entre os beneficiários e não-beneficiários, à probabilidade de $5 \%$ (cinco por cento). 
Tabela 5 - Distribuição absoluta e relativa dos beneficiários e nãobeneficiários, segundo a renda*, no município de QuixadáCE - 2008

\begin{tabular}{l|c|c|c|c}
\hline \multirow{2}{*}{ Renda } & \multicolumn{2}{|c|}{ Beneficiários } & \multicolumn{2}{c}{ Não-Beneficiários } \\
\cline { 2 - 5 } & $\begin{array}{c}\text { Freq. } \\
\text { Absoluta }\end{array}$ & $\begin{array}{c}\text { Freq. } \\
\text { Relativa } \\
\mathbf{( \% )}\end{array}$ & $\begin{array}{c}\text { Freq. } \\
\text { Absoluta }\end{array}$ & $\begin{array}{c}\text { Freq. } \\
\text { Relativa } \\
(\%)\end{array}$ \\
\hline Até 1 salário mín. & 17 & 37,8 & 4 & 26,7 \\
$1<$ salários mín. $\leq 2$ & 14 & 31,2 & 4 & 26,7 \\
$2 \leq$ salários mín. $\leq 3$ & 8 & 17,8 & 7 & 46,7 \\
$3 \leq$ salários mín. $\leq 4$ & 6 & 13,2 & 0 & 0,0 \\
Mais de 4 salários mín. & 0 & 0,0 & 0 & 0,0 \\
Total & $\mathbf{4 5}$ & $\mathbf{1 0 0 , 0}$ & $\mathbf{1 5}$ & $\mathbf{1 0 0 , 0}$ \\
Teste H-KW & \multicolumn{5}{c}{4,112} \\
Prob. Sig. & \multicolumn{4}{c}{0,046} \\
\hline
\end{tabular}

Fonte: Resultados da pesquisa.

(*)Considerando o salário mínimo de $\mathrm{R} \$ 415,00$.

A Tabela 6 mostra a comparação da renda das famílias entrevistadas. Para os não-beneficiários, $40 \%$ da renda vinha de pensões e aposentadorias, pois mais de $50 \%$ dos entrevistados tinham mais de 50 anos, e $34 \%$ vinha da agricultura, o que fazia com que a faixa salarial destes fosse maior que a dos beneficiários, pois a renda de pensões e aposentadoria era fixa. É importante citar uma porcentagem razoável da renda vinda do programa Bolsa-Família para as famílias beneficiadas e não-beneficiadas, o que mostra o grande alcance desse projeto de transferência de renda do governo federal, conforme trabalho de Rocha (2008).

No caso dos beneficiários, a maior parte da renda vinha da agricultura, principalmente da atividade de suinocultura, cuja participação era de $61 \%$, o que indica que os entrevistados beneficiários viviam diretamente de atividades agropecuárias e que o programa contribuía para isso. 
Tabela 6 - Distribuição relativa da renda dos beneficiários e nãobeneficiários, segundo fonte de renda, no município de Quixadá - CE - 2008

\begin{tabular}{l|c|c|c|c|c|c}
\hline $\begin{array}{c}\text { Fonte de } \\
\text { Renda (\%) }\end{array}$ & Agricultura & $\begin{array}{c}\text { Pensões e } \\
\text { Aposentadorias }\end{array}$ & $\begin{array}{c}\text { Bolsa- } \\
\text { Família }\end{array}$ & $\begin{array}{c}\text { Trabalho } \\
\text { Permanente }\end{array}$ & $\begin{array}{c}\text { Outras } \\
\text { Atividades }\end{array}$ & Total \\
\hline $\begin{array}{l}\text { Beneficiários } \\
\text { Bovinocultura }\end{array}$ & 38 & 16 & 11 & 12 & 23 & 100 \\
Ovinocultura & 46 & 21 & 13 & 15 & 5 & 100 \\
Suinocultura & 61 & 9 & 10 & 20 & 0 & 100 \\
Não-Beneficiários & 34 & 40 & 10 & 13 & 3 & 100 \\
\hline
\end{tabular}

Fonte: Resultados da pesquisa.

Mostrou-se relevante também a porcentagem do trabalho permanente, que variou de 12 a 20\%. No município de Quixadá, esses trabalhos permanentes eram desenvolvidos em escolas e hospitais da prefeitura, enquanto outras atividades, que enquadram o comércio em geral, tinham forte participação somente na atividade de bovinocultura, 23\%. Uma explicação para essa forte participação nessa atividade é que parte dos entrevistados, de início, realmente comprava animais com o dinheiro do financiamento, mas depois o vendiam, pois não conseguiam mantê-los. Dessa forma, eram obrigados a buscar outras fontes de renda que não fossem a agricultura e a pecuária.

\subsubsection{Média da renda agropecuária por hectare}

O Programa Agroamigo financia atividades agropecuárias que influenciam a renda das famílias beneficiadas. Para limitar a influência do tamanho da propriedade, foi calculada a renda agropecuária por hectare, a fim de comparar a renda dos beneficiários com a dos não-beneficiários. A Tabela 7 mostra que a média da renda agropecuária, por hectare, era maior na atividade de suinocultura e menor na de ovinocultura. Uma das explicações para a renda de a atividade de suinocultura ser maior que as outras atividades é que a taxa de nascimento e de venda de animais era bem menor que na bovinocultura, por exemplo, na qual os animais comprados precisavam de tempo maior para crescer e serem vendidos, em torno de 3 anos, o que atrasava o retorno financeiro, ao contrário da suinocultura, bem mais rápido, em torno de 6 meses. 
Tabela 7 - Média da renda agropecuária, por hectare, dos beneficiários e não-beneficiários, segundo as atividades pecuárias no município de Quixadá - CE - 2008

\begin{tabular}{c|c|c|c}
\hline \multicolumn{3}{|c|}{ Beneficiários } & Não-Beneficiários \\
\hline Bovinocultura & Ovinocultura & Suinocultura & \\
\hline 298,12 & 220,17 & 790,30 & 270,35 \\
\hline
\end{tabular}

Fonte: Resultados da pesquisa.

Com a finalidade de comparar a média da renda agropecuária, por hectare, entre as atividades dos beneficiários e dos não-beneficiários, aplicou-se o teste de Tukey, pelo qual se compara se as quatro médias mostradas na Tabela 8 possuem diferenças significativas entre elas.

Constatou-se que, dado o nível de significância de 5\% (cinco por cento), a média da renda agropecuária, por hectare, da atividade de suinocultura foi maior em relação às atividades de bovinocultura, ovinocultura e nãobeneficiário. Ao analisar as informações da Tabela 8, conclui-se que havia diferença significativa entre as médias das rendas agropecuárias, por hectare, das atividades de bovinocultura e suinocultura ( $\mathrm{p}$-valor $=$ $0,002<0,05)$, não-beneficiário e suinocultura ( $\mathrm{p}$-valor $=0,001<0,05) \mathrm{e}$ suinocultura e ovinocultura ( $\mathrm{p}$-valor $=0,001<0,05$ ). Na Tabela 7 , confirmase essa diferença significativa das médias, o que mostra que a média da renda agropecuária, por hectare, da suinocultura foi de $\mathrm{R} \$ 790,30$, mais que o dobro das outras atividades. 
Tabela 8 - Teste de Tukey para comparação da média da renda agropecuária, por hectare, entre as atividades de bovinocultura, ovinocultura, suinocultura e as atividades agropecuárias dos não-beneficiários, no município de Quixadá - CE - 2008

\begin{tabular}{l|l|c|c}
\hline $\begin{array}{l}\text { Renda Agropecuária } \\
\text { Média por Hectare }\end{array}$ & Atividades & $\begin{array}{c}\text { Diferenças entre } \\
\text { as Médias }\end{array}$ & Prob. Sig. \\
\hline Bovinocultura & Ovinocultura & 0,0616 & 0,931 \\
& Suinocultura & $-0,6677$ & 0,002 \\
& Não-Beneficiário & $-0,0460$ & 0,996 \\
Ovinocultura & Bovinocultura & $-0,0616$ & 0,931 \\
& Suinocultura & $-0,7293$ & 0,001 \\
\multirow{3}{*}{ Suinocultura } & Não-Beneficiário & $-0,1076$ & 0,980 \\
& Bovinocultura & 0,6677 & 0,002 \\
& Ovinocultura & 0,7293 & 0,001 \\
Não-Beneficiário & Não-Beneficiário & 0,6217 & 0,001 \\
& Bovinocultura & 0,0460 & 0,996 \\
& Ovinocultura & 0,1076 & 0,980 \\
& Suinocultura & $-0,6217$ & 0,001 \\
\hline
\end{tabular}

Fonte: Resultados da pesquisa.

\section{Conclusões e sugestões}

A mão-de-obra mais utilizada pelos entrevistados era a familiar. No entanto, no grupo dos beneficiários, a pecuária (bovinocultura e suinocultura) empregava o maior número de pessoas.

A renda da maioria dos beneficiários vinha da agricultura e a dos nãobeneficiários, de pensões e aposentadorias, o que mostra que o programa contribuiu para a renda agrícola dos beneficiários.

Dentre as atividades agropecuárias praticadas, a suinocultura mostrouse a mais rentável, dado o fato de o retorno financeiro ocorrer mais rápido que nas atividades de bovinocultura e ovinocultura. 
O Programa Agroamigo não contribuiu para melhorar a qualidade de vida das famílias beneficiadas, já que, em ambos os grupos, a qualidade de vida dos entrevistados foi classificada como média.

As maiores contribuições para o IQV vieram das condições de moradia, educação e saúde, e a menor, do lazer, indicadores que eram afetados diretamente por políticas públicas voltadas para construções de habitação, saneamento, escolas, postos de saúde, entre outros.

O Programa Agroamigo tem o objetivo de expandir o atendimento aos agricultores familiares de pequeno porte, por meio da concessão de microcrédito produtivo e orientado. A pesquisa observou que a concessão de empréstimos ocorreu de forma rápida e sem burocracia. Todavia, percebeu-se a necessidade de um acompanhamento rigoroso da aplicação dos recursos concedidos e de uma orientação aos agricultores sobre a melhor forma de atuação junto ao mercado.

Por fim, é válido ressaltar que as impressões, aqui relatadas, devem ser aprofundadas por meio de estudos posteriores para tornar possíveis conclusões definitivas acerca da eficiência e da efetividade do Agroamigo.

\section{Referências}

CARDOSO, Débora Freire; RIBEIRO, Claudiney Guimarães; ROCHA, Luiz Eduardo de Vasconcelos. Índice Relativo de Qualidade de Vida (IRQV) para as microrregiões mineiras: uma alternativa ao Índice de Desenvolvimento Humano (IDH), 2007, 24p.

DA VEIGA, José Eli. Nada Justifica o Apego ao PIB. Revista Valor Econômico, 2006, 3p.

GUERRERO, Solón J.; HOYOS, Luis Eduardo Acosta. Qualidade de vida: opção teórica e metodológica da qualidade de vida. Revista Econômica do Nordeste - REN , Brasília, v. 21, Abr/jun 1983, p.173 192. 
LIMA, Maria Lucinda da Silva; MENDONÇA, Marcos dos Santos; SILVA, Rubicleis Gomes; VIDAL, Marcelo Barbosa. Índice de Qualidade de Vida nos Municípios do Estado do Acre: Uma Aplicação da Estatística Multivariada. Universidade Federal do Acre, 2007, 18p.

MONTE, Francisca Silvânia de Sousa. Efeitos de implantação do Complexo Industrial e Portuário do Pecém - CE na qualidade de vida das famílias rurais da região: o caso do reassentamento Cambeba. Dissertação de mestrado, 1999. 144p.

NERI, Marcelo; MEDRADO, André Luiz. Experimentando Microcrédito: Uma Análise do Impacto do CrediAMIGO sobre Acesso a Crédito. Ensaios Econômicos. Escola de Pós-Graduação em Economia da Fundação Getúlio Vargas. Dezembro de 2005, 67p.

RHYNE, E.; HOLT, S. Women in Finance and Enterprise Development. Education and Social Police Discussion Paper 40, World Bank,Washington, D.C. 1994.

ROCHA, Leonardo Andrade. O Impacto do Programa Bolsa Família sobre o bem estar das famílias beneficiadas no Estado do Ceará. Dissertação de Mestrado. Universidade Federal do Ceará, 2008, 82p.

VIANA, Lenival Santiago et al. Qualidade de vida no meio rural brasileiro: o caso do sertão de Alagoas. Revista de Economia e Sociologia Rural. Brasília, v. 18, n. 2, 1980, p. 182-204. 
Abstract: The main objective of the study is to verify the impact of program of small agricultural credit on the quality of life of the benefited families in the state of Ceara. The data was obtained through the application of questionnaires to the benefited families in the county of Quixada. Table, graphic and descriptive analysis were used to describe the collected data. The t-student, Tukey test and Kruskall-Wallis test were used to compare the mean values of selected variables and proportions of benefited and non benefited families were used, respectively. The employment per hectare cultivated is higher on the properties having cattle breeding and hog production activities financed by the credit program. The main of income of benefited and non benefited families is agriculture and retirement and pension, respectively. The average income per hectare cultivated is higher from hog production due to rapid returns as compare to cattle breeding and goat and sheep raising activities. The benefited and non benefited families have the average quality of life. The living condition, access to education and health facilities contributed the most in the formation of life quality index and leisure facilities contributed less in improving the quality of life of the benefited and non benefited families.

Keywords: small rural credit, employment, income, quality of life, Ceará. 
REVISTA DE ECONOMIA E AGRONEGÓCIO, VOL.7, $N^{\circ} 1$ 